\title{
Editorial
}

\section{PSICOLOGIA AMBIENTAL: REVISANDO, REVISITANDO E RESSIGNIFICANDO}

$\mathrm{O}$ nze anos se passaram do número Monográfico de Psicologia Ambiental publicado na revista Estudos de Psicologia (Natal) em 2003, pelo professor Jose Pinheiro (UFRN), para este número especial da revista Psico da PUCRS em 2014. Enquanto o primeiro se destacou por seu ineditismo, uma vez que haviam escassos trabalhos empíricos produzidos e publicados em revistas do país, possibilitando a circulação de artigos da área de Psicologia Ambiental em português, este que apresentamos, se destaca pela já expressiva produção brasileira e latina americana de Psicologia Ambiental e o crescente intercambio entre pesquisadores de continentes diversos. Muitos avanços foram conquistados neste período por Programas de Pós-Graduação nas universidades brasileiras, destacando-se a interdisciplinaridade, como uma característica peculiar desta área. Em vários programas, teses e dissertações tem sido defendidas, sendo este campo hoje, recomendado pelos órgãos de fomento como área a ser incrementada nos Programas de Pós-Graduação em Psicologia devido a crescente demanda na pós-graduação.

Pouco mudou em relação à crise ambiental que era apontada em anos anteriores, pelo contrario, as mudanças climáticas e o aumento da temperatura global continuam enfatizando que os impactos ambientais e a exiguidade dos recursos naturais tem como marca o estilo de vida e o comportamento humano como grande responsável. Esta tem sido "a temática", e a grande questão na contemporaneidade, que tem suscitado muitos estudos e pesquisas em Psicologia Ambiental. É fato também que estudar o espaço e ou ambiente não pode prescindir dos aspectos psicossociais e do contexto social advindos da globalização e da sustentabilidade (Moser, 2001). Neste sentido, algumas questões orientam a construção deste número: Quais os desafios atuais da Psicologia Ambiental? Novos desafios se configuram para a Psicologia Ambiental neste momento em que a vida das cidades aponta grandes conflitos da vida societal - Como integrar o ambiente construído com a natureza? Como integrar uma cidade sustentável com justiça social?

Tendo em vista este panorama apresentado, para dar conta dos objetivos do número especial, que foi o de discutir como a Psicologia Ambiental tem respondido às demandas ambientais atuais e como tem revisado e ressignificado seus conceitos neste processo de consolidação da área, selecionamos os artigos para o monográfico que melhor representassem esse momento. Em primeiro lugar, realizamos convites para submissão dirigidos a autores específicos, ou seja, aqueles que corresponderam à demanda do número da revista com produção significativa, considerando as exigências formais e normas da revista. Neste sentido, o número conta com dois artigos que provém de pesquisadores consagrados e de extensa produção na área: Juan Ignácio Aragonés e Sergi Valera, representantes da PSICAMB (Asociación Española de Psicologia Ambiental) e Ricardo Garcia Mira da IAPS (International Asociation of People Environment Studies). Face ao grande volume de artigos recebidos, foram selecionados 15 artigos que, passaram pelo processo de blind review, realizado por no mínimo dois pareceristas da área, provenientes de diversos países: Portugal, Espanha, México, Nova Zelândia, Turquia e Brasil. Dentre os temas que abordaremos neste número, destacamos um artigo Histórico que apresenta a evolução da psicologia ambiental no âmbito da Associação de Psicologia Ambiental europeia (Juan Ignácio Aragonés e Sergi Valera) e dois grandes blocos: Espaços abertos, ambientes naturais e construídos (Ana Paula Soares e Eda Tassara; Ana Loureiro; Cíntia Viegas, Eduardo Silva e Gleice Elali; Romina Caballero, Paul Franco, Alba Mustaca e Adriana Jakovcevic; Esther Wiesenfeld; Zenith Delabrida [encarte digital]); Comportamento Pró-Ambiental e Sustentabilidade (Ricardo Garcia Mira, Adina Dumitru, Pedro 
Vega-Marcote; Fabio Iglesias, Lucas Caldas e Luisa Rabelo; Ignacio Pisano e Carmen Hidalgo; Pablo Olivos, Fernando Talayero, Juan Ignácio Aragonés e Emílio Moyano; Emilio Moyano, Gonzalo Palomo-Vélez; Maria Amérigo e Juan Garcia; Raquel Diniz e José Pinheiro; Taciano Milfont, Paul Brain, Roosvelt Souza, Valdiney Gouveia e Yoshihisa Kashima).

Enquanto editoras convidadas, agradecemos à revista Psico pelo convite e confiança depositada. Da mesma forma, agradecemos aos pareceristas pelo comprometimento com esta tarefa, e aos autores que ao submeter seus artigos, nos brindaram com suas produções. Agradecemos também aos parceiros estratégicos do GT de Psicologia Ambiental da Associação Nacional de Pesquisa e Pós-Graduação em Psicologia (ANPEPP), e de outras instituições de Psicologia Ambiental internacionais como Asociación de Psicología Ambiental (Psicamb), Sociedade Interamericana de Psicologia (SIP) e International Association People Environment Studies (IAPS). A composição de um Conselho Consultivo internacional (México: Victor Corral-Verdugo; Venezuela: Esther Wiesenfeld; Espanha: Enric Pol e Bernardo Hernandes; Brasil: José Pinheiro e Hartmut Günther) com experiência e produtividade na área foi fundamental para o desenvolvimento e elaboração deste número. E por último destacamos a importância das associações científicas como um importante espaço de crescimento, produção, difusão da área e de intercâmbio do pesquisador que, neste momento, as editoras representam um deles: a coordenação do GT de Psicologia Ambiental da Sociedade Interamericana de Psicologia. Esperamos que este número monográfico de Psicologia Ambiental da revista Psico venha contribuir para a expansão e consolidação da área de Psicologia Ambiental no Brasil, América Latina e Europa, assim como propiciar intercâmbios e a internacionalização decorrente desta produção.

Camila Bolzan de Campos

Bolsista de pós-doutorado da Programa de Pós-Graduação em Arquitetura da Universidade Federal do Rio Grande do Sul - UFRGS (CAPES/FAPERGS) Zulmira Áurea Cruz Bomfim Professora do Programa de Pós-Graduação em Psicologia da Universidade Federal do Ceará (UFC) 